\title{
DECLINE IN HISTONE H5 PHOSPHORYLATION DURING ERYTHROID SENESCENCE IN CHICK EMBRYOS
}

\author{
MICHAEL PIKAART ${ }^{a, b}$, JOHN IRVING ${ }^{a}$ and BRYANT VILLEPONTEAU ${ }^{a, b}$ \\ "The Institute of Gerontology and hDepartment of Biological Chemistry. University of Michigan. Ann \\ Arbor, Michigan (U.S.A.) \\ (Received December 10th, 1990)
}

\section{SUMMARY}

Previous studies have implicated histone H5 dephosphorylation as a causal factor in genetic inactivation and chromatin condensation during erythroid senescence in adult chickens. We show that histone $\mathrm{H} 5$ phosphorylation declines in two stages as various cohorts of erythroid cells senesce in chick embryos. The first decline occurs between 5 and 6 days and coincides with the senescence of primitive erythrocytes. The second decline in $\mathrm{H} 5$ phosphorylation occurs between 17 and 19 days of chicken development, when the definitive erythrocytes undergo senescence and chromatin condensation. These results point to a role for histone dephosphorylation during the programed senescence of erythroid cells.

Key words: Chicken erythrocytes; Senescence; Histones; Phosphorylation

\section{INTRODUCTION}

During differentiation and senescence, the avian erythroid cell loses its capacity for division and transcription. This loss of genetic activity is generally attributed to chromatin condensation, which decreases the accessibility of the DNA to transcription factors [1-4]. At the molecular level, genetic inactivation and chromatin condensation are apparently facilitated by increases in the cell's complement of histone H5 [1,3,5], an avian-specific linker histone which shares structural and functional homologies with the H1 family of mammalian histones [6,7]. The H1 family of

Correspondence to: Bryant Villeponteau, Institute of Gerontology, 300 North Ingalls, Ann Arbor, MI 48109-2007 U.S.A. 
linker-specific histones is involved in condensing chromatin into the $30-\mathrm{nm}$ fiber [8]. Like its mammalian cognate $\mathrm{H} 1^{\circ}$, synthesis of $\mathrm{H} 5$ is not replication dependent but rather increases postmitotically $[2,9,10]$. As a result, $\mathrm{H} 5$ accumulates in senescent terminally differentiated erythrocytes [1].

The accumulation of $\mathrm{H} 5$ with its high lysine content could account for the genetic inactivation of the erythroid nucleus by condensing chromatin and rendering the DNA less accessible to regulatory proteins. However, histone $\mathrm{H} 5$ is also present at significant levels in young dividing erythroblasts, so that the 3-to 5-fold increase in $\mathrm{H} 5$ concentration observed during senescence may not be sufficient to fully account for the erythroid-specific chromatin condensation [1,3]. Therefore, Sung [3] has postulated that post-translational phosphorylation and subsequent dephosphorylation of $\mathbf{H} 5$ play a significant role in inducing chromatin condensation and repressing genetic activity during senescence. Presumably, dephosphorylation of H5 increases the charge attraction between histones and DNA by reducing the negative charge on H5. Support for this hypothesis has come from data showing that $\mathbf{H} 5$ becomes progressively less phosphorylated as erythroid cells senesce in adult chickens made anemic by phenylhydrazine [2,3].

In the adult chicken, erythroid senescence occurs asynchronously from precursor cells in the bone marrow. To date, investigations of H5 phosphorylation have been carried out using adult chickens in which erythroid senescence is synchronized by treatment with phenylhydrazine to lyse mature erythrocytes [2-4]. By contrast, chick embryos provide a natural, drug-free system in which to study synchronized erythroid senescence. Primitive erythroid cells senesce at 5 to 6 days of development and are replaced by definitive erythroid cells, which senesce between 17 and 19 days of embryonic development. In this report, we have used the chick primitive and definitive cohorts to investigate stage-specific $\mathrm{H} 5$ dephosphorylation during programed embryonic erythroid senescence. We report significant changes in the levels of H5 phosphorylation at the two stages of erythroid senescence, suggesting that $\mathrm{H} 5$ phosphorylation plays a role in the senescence of both the primitive and definitive cohorts of erythroid cells.

\section{MATERIALS AND METHODS}

\section{Preparation of red blood cells}

Fertile chicken eggs were incubated at $39^{\circ} \mathrm{C}$ until the desired time of development, at which time the eggs were opened. Blood was collected with a pasteur pipette and dispensed into ice-cold $0.14 \mathrm{M} \mathrm{NaCl}, 2.7 \mathrm{mM} \mathrm{NaCl}, 1.5 \mathrm{mM} \mathrm{KH}_{2} \mathrm{PO}_{4}$ and the erythroid cells were pelleted at $1500 \times g$ for $5 \mathrm{~min}$. Nuclei were isolated by resuspending the cells in $1 \mathrm{ml}$ lysis buffer $(10 \mathrm{mM}$ Tris $(\mathrm{pH} 7.4), 10 \mathrm{mM} \mathrm{NaCl}, 3 \mathrm{mM}$ $\mathrm{MgCl}_{2}, \quad 0.3 \mathrm{M}$ sucrose, $40 \%$ glycerol v/v, $0.4^{\mathrm{\omega}} \%$ nonidet $\mathrm{P}-40 \mathrm{v} / \mathrm{v}, 1 \mathrm{mM}$ p-chloromercuriphenyl-sulfonic acid) and pelleting in a microfuge for $3 \mathrm{~min}$. 


\section{Histone extraction}

Histones were prepared by extracting the nuclei in $0.2 \mathrm{M} \mathrm{H}_{2} \mathrm{SO}_{4}$ at $4^{\circ} \mathrm{C}$ for $4 \mathrm{~h}$, pelleting in the microfuge for $15 \mathrm{~min}$ at $4^{\circ} \mathrm{C}$ to remove nuclear debris, and precipitating the histones with three volumes of ethanol $\left(-20^{\circ} \mathrm{C}, 12 \mathrm{~h}\right)$. Total histone concentration was determined by measuring the absorbance at $230 \mathrm{~nm}$. Histones were resuspended in $1 \mathrm{mM} \mathrm{HCl}$ at $1 \mathrm{mg} / \mathrm{ml}$.

\section{Electrophoretic analysis}

High-resolution acetic acid-urea polyacrylamide gels were prepared according to the method of Hardison and Chalkley [11] consisting of $2.5 \mathrm{M}$ urea, $0.9 \mathrm{M}$ acetic acid, $15 \%$ polyacrylamide, and were cast in $32 \mathrm{~cm}$ plates. The gels were preelectrophoresed in an electrode buffer of $2.5 \mathrm{M}$ urea, $0.9 \mathrm{M}$ acetic acid for $24 \mathrm{~h}$ at $100 \mathrm{~V}$. Fifty micrograms of histone were loaded per lane at a concentration of 1 $\mathrm{mg} / \mathrm{ml}$ in $2.5 \mathrm{M}$ urea, $0.9 \mathrm{M}$ acetic acid and run in $0.9 \mathrm{M}$ acetic acid at $250 \mathrm{~V}$ for $36 \mathrm{~h}$. When electrophoresis was complete, the gels were fixed in $12.5 \%$ trichloroacetic acid and stained with silver stain (Sigma). After staining, the gels were dried between cellophane for photography and densitometer scanning. When acid-extracted histones from developing chick embryos were separated on acid-urea gels and silver stained, a characteristic spread of core, H1, and H5 histones was observed (Fig. 1). Quantitation was carried out on a Hoefer densitometer and analyzed using Gel Scan computer software.

\section{RESULTS}

Incubation of adult erythrocyte in medium containing various radioactive precursors has demonstrated that histone $\mathrm{H} 5$ is post-translationally modified by phosphorylation but not by acetylation or methylation [2]. Radiolabeled phosphorylated H5 variants from adult erythrocytes have been successfully fractionated by electrophoresis on urea-aluminum lactate starch gels $[3,4]$. Although phosphorylated H5 subfractions are not well separated on shorter acid-urea gels (see Ref. 5), we have obtained good separation of phosphorylated H5 variants from embryonic erythroid histones using high-resolution electrophoresis on $32 \mathrm{~cm}$ acid-urea gels (see 5 day sample in Fig. 1). The slower migrating $\mathrm{H} 5$ subbands $\left(\mathrm{P}_{1}-\mathrm{P}_{4}\right.$ in Fig. 2$)$ have been verified as phosphorylated $\mathrm{H} 5$ by their sensitivity to alkaline phosphatase digestion (data not shown). $\mathrm{P}_{0}$ and $\mathrm{P}_{0}{ }^{\prime}$, which remain after phosphatase treatment, represent known H5 variants [5].

As previously demonstrated for adult chickens [2,3], Fig. 1 shows that histone H5 becomes dephosphorylated during erythroid senescence. To better illustrate these changes, densitometer tracings of $\mathrm{H} 5$ variants (Fig. 2) were prepared from the gel shown in Fig. 1. Figure 2 demonstrates a significant loss of the phosphorylated variants $\mathrm{P}_{1}-\mathrm{P}_{4}$ during development at 5,12 and 20 days, so that by 20 days nearly 


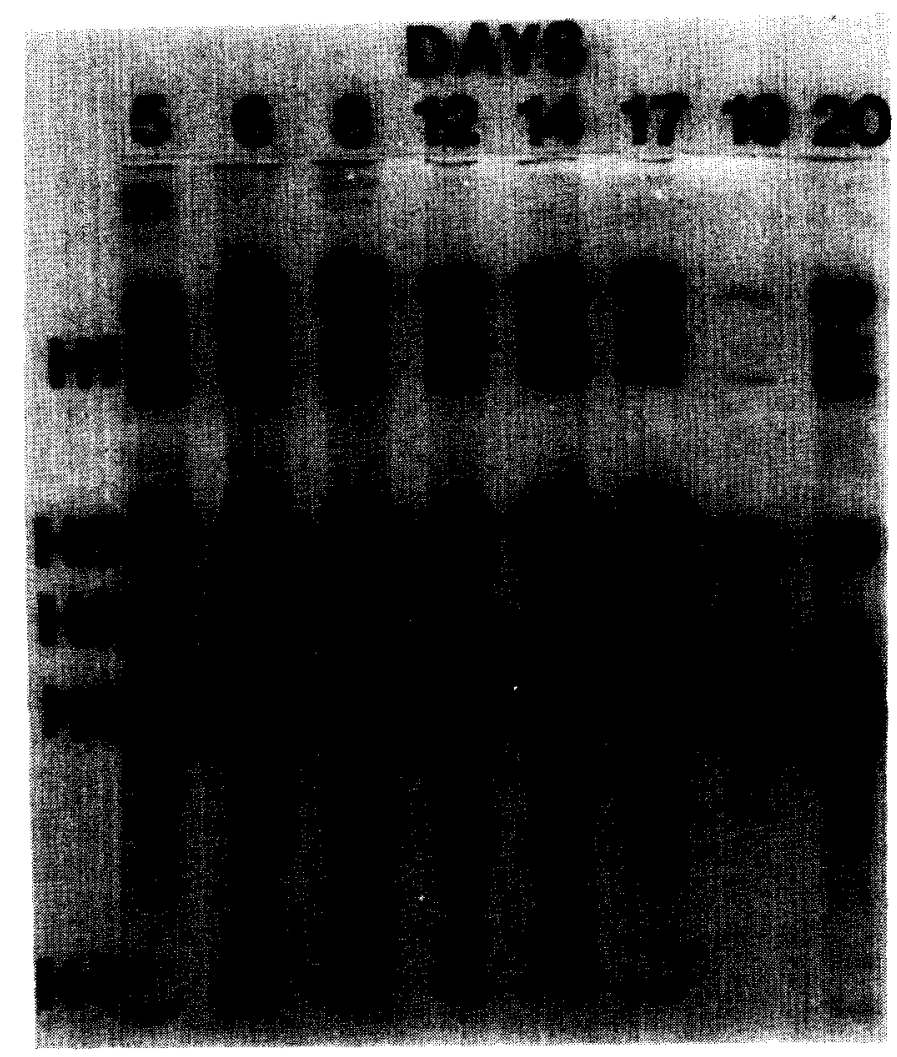

Fig. 1. Acid-urea gel showing fractionation of erythroid histones from through 20 day chick embryos. Note that histones from 19- and 20-day erythrocytes are underloaded in this gel.

all the $\mathrm{H} 5$ is in the dephosphorylated $\mathrm{P}_{0}$ or $\mathrm{P}_{0}{ }^{\prime}$ form. To quantitate these changes, the areas under the two non-phosphorylated $\mathrm{H} 5$ peaks $\left(\mathrm{P}_{0}\right.$ and $\left.\mathrm{P}_{0}{ }^{\prime}\right)$ were divided by the total $\mathrm{H} 5$ areas for two duplicate gels. Figure 3 shows the increase during development in the fraction of the total H5 which is non-phosphorylated. Significantly, this dephosphorylation is not gradual but occurs in two bursts, first at 5--6 days and next at 17-19 days.

\section{DISCUSSION}

As in adult erythropoiesis, we have observed a correlation between erythroid senescence and dephosphorylation of histone H5. However, dephosphorylation in embryonic cells is not gradual but occurs in two temporally defined bursts that are coincident with senescence of primitive and definitive erythroid cells. The change between 5 and 6 days of embyronic development is concurrent with the senescence of 




5 day



12 day

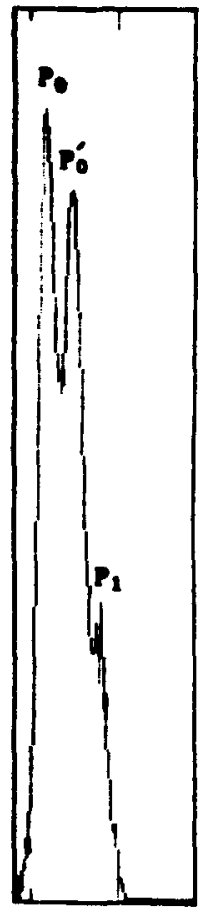

20 day

Fig. 2. Densitometer tracings of the $\mathrm{H} 5$ histone variants from 5-, 12- and 20-day embryos. The lanes in Fig. 1 containing histones from 5, 12, and 20 day embryos were scanned with a densitometer. The 20-day tracing has been normalized to compensate for histone underloading in this lane. $P_{0}$ and $P_{0}$ ' represent non-phosphorylated $\mathrm{H} 5$ variants while $\mathrm{P}_{1}-\mathrm{P}_{\mathbf{4}}$ represent phosphorylated $\mathrm{H} 5$ variants.

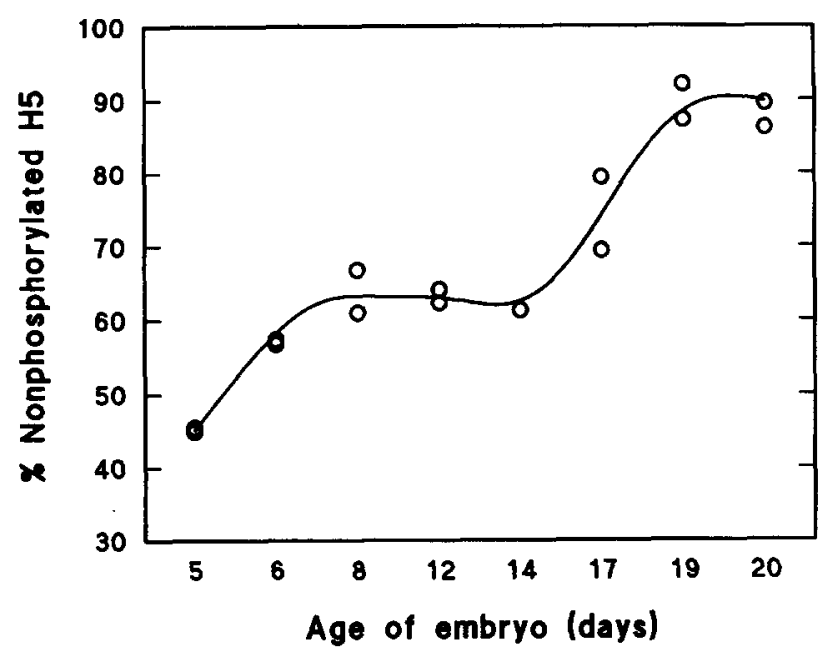

Fig. 3. Non-phosphorylated $\left(P_{0}\right.$ and $\left.P_{0}{ }^{\prime}\right)$ and phosphorylated $\left(P_{1}-P_{4}\right)$ HI variants as a percent of total H5. Data were obtained by averaging the densitometer values from two acid-urea gels. 
the primitive cohort (expressing only embryonic globins) and with their replacement by the definitive cohort (expressing mostly adult globins-see ref. 12 and 13). The next burst of dephosphorylation occurs between 17 and 19 days at the stage when the definitive cohort becomes transcriptionally inactive as fully senescent erythrocytes [5]. Thus H5 dephosphorylation is closely associated with changes in gene expression and with senescence.

Previously reported observations are consistent with a causal role for H5 dephosphorylation in gene repression and chromatin condensation. First, histone phosphorylation makes chromatin more sensitive to DNase I digestion [14], indicating a more open chromatin structure. Thus $\mathrm{H} 5$ dephosphorylation should lead to tighter binding of $\mathrm{H} 5$ to DNA, greater DNA condensation, and less accessibility to transcription factors. Second, the decline in $\mathrm{H} 5$ phosphorylation between 17 and 19 days and subsequent chromatin condensation are reminiscent of protamine dephosphorylation prior to chromatin condensation during spermatogenesis $[15,16]$. Phosphorylated protamines largely replace the spermatocyte histones and are then progressively dephosphorylated. The highly basic, dephosphorylated protamine functions to package the chromatin tightly inside the compact sperm and at the same time inactivates transcription. In the same way, an increase in the erythroid $\mathrm{H} 5$ complement and its subsequent dephosphorylation could well explain the similar condensation and genetic inactivation during erythroid senescence.

As to the role of dephosphorylation in senescent cells, our results with erythrocytes indicate that nuclear dephosphorylation rates may be elevated in senescent cells. If so, other proteins besides the histones could be dephosphorylated. Support for this view comes from recent data demonstrating that the antigrowth retinoblastoma gene is dephosphorylated in senescent human fibroblasts [17]. Since phosphorylation plays a major role in regulating proteins, enhanced rates of dephosphorylation in senescence could affect many cellular processes.

\section{ACKNOWLEDGMENTS}

This research was supported in part by a grant from the American Federation For Aging Research (AFAR).

\section{REFERENCES}

1 M. Weintraub, The nucleosome repeat increases during erythropoiesis in the chick. Nucl. Acids Res.. 5 (1978) $1179-1188$.

2 M.T. Sung, J. Harford, M. Bundman and G. Vidalakas, Metabolism of histones in avian erythroid cells. Biochemistry, 16 (1977) 279-285.

3 M.T. Sung, Phosphorylation and dephosphorylation of histone V (H5): Controlled condensation of avian erythrocyte chromatin. Biochemistry, 16 (1977) 286-290.

4 M.T. Sung and E.F. Freedlender, Sites of in vivo phosphorylation of histone H5. Biochemistry, 17 (1978) $1884-1890$. 
5 B.A. Moss, W.G. Joyce and V.M. Ingram, Histones in chick embryonic erythropoiesis. J. Biol. Chem., 248 (1973) 1025-1031.

6 J. Sun, R. Wiaderkiewicz and A. Ruiz-Carrillo, Histone H5 in the control of DNA synthesis and cell proliferation. Science, 245 (1989) 68-71.

7 D. Doenecke and R. Tonjes, Differential distribution of lysine and arginine residues in the closely related histones $\mathrm{H} 1$ and H5-analysis of a human HI gene. J. Mol. Biol., 187 (1986) 461-464.

8 J.T. Finch and A. Klug, Solenoidal model for superstructure in chromatin. Proc. Natl. Acad. Sci. USA, 73 (1976) 1897-1901.

9 R. Gjerset, C. Gorka, S. Hasthorpe, J.J. Lawrence and H. Eisen, Developmental and hormonal regulation of protein $\mathrm{H}^{\circ}$ in rodents. Proc. Natl. Acad. Sci. U.S.A., 79 (1982) 2333-2337.

10 A.F.M. Moorman, P.A.J. de Boer, W.H. Lamers and R. Charles, The cellular distribution of histone H5 in embryonic and adult tissues of Xenopus laevis and chicken. Acta Histochemien, Suppl.-Band $X X X I I, S$. (1986) 105-109.

11 R. Hardison and R. Chalkley, In G. Stein, J. Stein and L.J. Kleinsmith (eds.), Methods In Cell Biology, Vol. 17, p. 235. Academic Press, New York, 1978, p.235.

12 B. Villeponteau, G.M. Landes, M.J. Pankratz and H.G. Martinson, Delineation of transcription units and developmental regulation of interspersed DNA repeats. J. Biol. Chem., 257 (1982) $11015-11023$.

13 G.M. Landes, B. Villeponteau, T.M. Pribyl and H.G. Martinson, Hemoglobin Switching in chickens: Is the switch initiated post-transcriptionally? J. Biol. Chem., 257 (1982) 11008-11014.

14 M.H. West, P. Pantazis and W.M. Bonner, Studies on Nuclease Digestion of chromatin phosphorylation in vivo. J. Biol. Chem., 260 (1985) 4558-4560.

15 A.J. Louie and G.H. Dixon, Kinetics of enzymatic modification of the protamines and a proposal for their binding to chromatin. J. Biol. Chem., 247 (1972) $5490-5497$.

16 M.T. Sung and G.H. Dixon, Modification of histones during spermiogenesis in trout: A moleculatar mechanism for altering histone binding to DNA. Proc. Natl. Acad. Sci. U.S.A., 67 (1970) $1616-1620$.

17 G.H. Stein, M. Beeson and L. Gordon, Failure to phosphorylate the retinoblastoma gene in senescent human fibroblasts. Science, 249 (1990) 666-669. 